\title{
A Simple New Route to Covalent Organic/Inorganic Hybrid Proton Exchange Polymeric Membranes
}

\author{
M. Luisa Di Vona, ${ }^{*, \dagger}$ Debora Marani,${ }^{\dagger}$ Cadia D’Ottavi,${ }^{\dagger}$ Marcella Trombetta, ${ }^{\ddagger}$ \\ Enrico Traversa ${ }^{\dagger}$ Isabelle Beurroies, ${ }^{\S}$ Philippe Knauth, ${ }^{\S}$ and Silvia Licoccia ${ }^{\dagger}$ \\ Dipartimento di Scienze e Tecnologie Chimiche, Università di Roma Tor Vergata, via della Ricerca \\ Scientifica 1, 00133 Roma, Italy, C.I.R.-Centro Interdisciplinare di Ricerca, Università Campus \\ Bio-Medico, via Longoni 83, 00155 Roma, Italy, and MADIREL (UMR 6121 CNRS), \\ Université de Provence, Centre St Jérôme, 13397 Marseille Cedex 20, France
}

Received July 15, 2005. Revised Manuscript Received November 4, 2005

\begin{abstract}
The development of proton exchange membranes as electrolytes for polymer electrolyte fuel cells operating at intermediate temperatures has been achieved combining two approaches: the preparation of a cross-linked polymer and the formation of covalent organic/inorganic hybrids. A covalently crosslinked sulfonated polyetheretherketone with elevated degree of sulfonation ( $\mathrm{DS}=0.8$ ) was prepared by reaction with $\mathrm{HSO}_{3} \mathrm{Cl}$ (SOPEEK). No degradation of PEEK was detected upon sulfonation, but only cross-linking via sulfonic groups with formation of $\mathrm{SO}_{2}$ moieties was observed. The extent of ramification was calculated by analyzing the ${ }^{1} \mathrm{H}$ nuclear magnetic resonance (NMR) spectra of the products and resulted in $20 \%$ of the total amount of $-\mathrm{SO}_{3} \mathrm{H}$ groups present in the polymer. The solubility of the $-\mathrm{SO}_{2} \mathrm{Cl}$ precursor in organic solvents allowed easy carrying out of functionalization reactions in homogeneous conditions by lithiation and subsequent reaction with $\mathrm{SiCl}_{4}$, thus introducing covalenly linked silicon moieties (SOSiPEEK) at the ratios 1:0.25 and 1:0.50 per monomeric unit. The products were characterized by ${ }^{1} \mathrm{H}$ and ${ }^{13} \mathrm{C}$ NMR, attenuated total reflectance Fourier transform infrared spectroscopy, thermogravimetric analysis, and differential scanning calorimetry.
\end{abstract}

\section{Introduction}

High-performance thermoplastic polymers are currently receiving considerable attention for their potential applications in various industries. In particular, aromatic polyetherketones and polysulfones are known to have excellent hightemperature resistance, mechanical strength, and oxidation stability. ${ }^{1-3}$ Unless carefully designed, however, aromatic polymers are insoluble in most organic solvents, which makes it difficult to use these systems as substrates for further functionalization. Therefore, much effort has been spent on preparing processable aromatic polymers by changing the chemical nature of the macromolecule to some degree, while maintaining its desired properties. ${ }^{4}$

One recent and promising application of aromatic polymers is in the field of ion-conductive membranes for fuel cells. ${ }^{4-6}$ In fuel cells, the ionomer membrane acts both as separator

* Corresponding author. E-mail: divona@uniroma2.it. Tel: +39-06-72594385. Fax: +39-06-7259-4328

$\dagger$ Università di Roma Tor Vergata.

¥ Università Campus Bio-Medico.

§ Université de Provence.

(1) Harrison, W. L.; Hickner, M. A.; Kim, Y. S.; McGrath, J. E. Fuel Cells 2005, 5, 201.

(2) Jin, X.; Bishop, M. T.; Ellis, T. S.; Karasz, F. E. Br. Polym. J. 1985 $17,4$.

(3) Mark, J. Polyetheretherketones. In Encyclopaedia of Polymer Science and Engineering; May R., Ed.; J. Wiley \& Sons: New York, 1988; Vol. 13, p 313.

(4) Hickner, M. A.; Ghassemi, H.; Kim, Y. S.; Einsla, R.; McGrath, J. Chem. Rev. 2004, 104, 4587.

(5) Alberti, G.; Casciola, M.; Massinelli, L.; Bauer, B. J. Membr. Sci. 2001, $185,73$.

(6) Kerres, J. A. J. Membr. Sci. 2001, 185, 3. between the two electrodes and as electrolyte for proton transport. To create proton conductivity, polymers can be modified introducing acidic units into aromatic rings, generally by sulfonation reaction. There are, however, a number of specific requirements to consider for designing new polymers for polymer electrolyte membrane fuel cells (PEMFCs): first, mechanical strength and dimensional stability of membranes in a hydrated state at intermediate temperatures $\left(80-130{ }^{\circ} \mathrm{C}\right)$, and second, retention of water to maintain hydration. Then, the oxidative stability of the polymer chain containing sulfonic acid groups, as well as the morphology of the polymer electrolyte membranes (PEMs) to achieve structures with phase separation of hydrophobic domains and hydrophilic ionic domains must be taken into account. ${ }^{7-9}$ Furthermore, a high degree of sulfonation (DS) is necessary to obtain adequate conductivity, but as the number of sulfonic acid groups per repeat unit increases, the polymers become more swollen and mechanically too weak to be used in PEMFCs. Sulfonation, in fact, modifies the chemical behavior of polymers, reduces crystallinity, and consequently, affects solubility. ${ }^{10,11}$

A more complex polymer architecture must therefore be designed to achieve the requested performance: hydrophobic

(7) Hickner, M. A.; Pivovar, B. S. Fuel Cells 2005, 5, 213.

(8) Jannasch, P. Fuel Cells 2005, 5, 248

(9) Li, Q.; He, R.; Jensen, J. O.; Bjerrum, N. J. Chem. Mater. 2003, 15, 4896.

(10) Kaliaguine, S.; Mikhailenko, S. D.; Wang, K. P.; Xing, P.; Robertson, G.; Guiver, M. Catal. Today 2003, 82, 213.

(11) Robertson, G. P.; Mikhailenko, S. D.; Wang, K.; Xing, P.; Guiver, M. D.; Kaliaguine, S. J. Membr. Sci. 2003, 219, 113. 
rigid thermoplastic polymer main chains for mechanical and chemical stability, combined with more flexible and hydrophilic sulfonated graft chains. This different architecture is expected to accentuate the phase separation between the hydrophobic and hydrophilic domains, which is a factor controlling the water channeling and proton conductivity in PEMFCs. ${ }^{12,13}$

Among the several approaches that can be used to improve ionomeric membranes, two seem to be the most interesting: the preparation of cross-linked polymers and the formation of covalent organic-inorganic hybrid membranes. ${ }^{14,15}$

Recently, we reported a method for the formation of a Class II organic/inorganic hybrid polymer, where the organic and inorganic moieties were linked through covalent bonds. ${ }^{16}$ Organic/inorganic hybrids are investigated for a variety of applications: such materials, in fact, can exhibit properties intermediate between those of the organic and inorganic components. Furthermore, the interaction at the molecular level, in Class II hybrids, allows a much finer tailoring of the final properties of the material. ${ }^{17,18}$

In this work we combined the two approaches preparing a covalently cross-linked polyetheretherketone with elevated DS by sulfonation reaction (SOPEEK) and further functionalized it by silylation reaction (SOSiPEEK). A general, efficient, and experimentally simple method for the introduction of silicon functional groups into polymeric carbon frameworks was developed.

\section{Experimental Section}

Caution: Chlorosulfonic acid $\left(\mathrm{HSO}_{3} \mathrm{Cl}\right)$ and chlorinated solvents are hazardous and should be handled with proper precautions, under a chemical hood with a fume exhaust system.

Materials. Polyetheretherketone (Victrex, PEEK, 450 PF, MW $=38300$ ), $\mathrm{HSO}_{3} \mathrm{Cl}$ (Fluka), and all other chemicals (Aldrich) were reagent grade and were used as received. Anhydrous THF and $\mathrm{CH}_{2-}$ $\mathrm{Cl}_{2}$ were prepared according to literature procedures. ${ }^{19,20}$

Sulfochlorination of PEEK. PEEK ( $2.5 \mathrm{~g}, 8.7$ mequiv) was added to $\mathrm{HSO}_{3} \mathrm{Cl}(10 \mathrm{~mL})$ and the mixture was stirred at $50{ }^{\circ} \mathrm{C}$ in a nitrogen atmosphere. After $1 \mathrm{~h}$, the polymer was completely dissolved, giving a viscous orange solution. After the mixture was further stirred for $4 \mathrm{~h}$ at $50{ }^{\circ} \mathrm{C}$, it was cooled to RT and the polymer was precipitated by addition of anhydrous $\mathrm{CH}_{2} \mathrm{Cl}_{2}(100 \mathrm{~mL})$. The mixture was stirred for $10 \mathrm{~min}$, then the solvent was rapidly removed under nitrogen, and fresh anhydrous $\mathrm{CH}_{2} \mathrm{Cl}_{2}(40 \mathrm{~mL})$ was added. The procedure was repeated several times, washing the precipitate to neutral $\mathrm{pH}$.

Hydrolysis of Sulfochlorinated PEEK: Synthesis of SOPEEK. Sulfochlorinated PEEK was added to a saturated solution of

(12) Kreuer, K. D. J. Membr. Sci. 2001, 185, 29.

(13) Yang, Y.; Holdcraft, S. Fuel Cells 2005, 5, 171

(14) Honma, I.; Nishikawa, O.; Sugimoto, T.; Nomura, S.; Nakajima H. Fuel Cells 2002, 2, 52.

(15) Kerres, J. A. Fuel Cells 2005, 5, 230.

(16) Di Vona, M. L.; Marani, D.; D'Epifanio, A.; Traversa, E.; Trombetta, M.; Licoccia, S. Polymer 2005, 46, 1754

(17) Sanchez, C.; De A. A.; Soler-Illia, G. J.; Ribot, F.; Grosso, D. C. $R$ Chim. 2003, 6, 1131.

(18) Haas, K. H.; Rose, K. Rev. Adv. Mater. Sci. 2003, 5, 47.

(19) Furniss, B. S.; Hannaford, A. J.; Smith, P. W. G.; Tatchell, A. R. Texbook of Practical Organic Chemistry; Vogel's Longman Scientific \& Technical: Essex, U.K., 1989; p 406.

(20) Furniss, B. S.; Hannaford, A. J.; Smith, P. W. G.; Tatchell, A. R. Texbook of Practical Organic Chemistry; Vogel's Longman Scientific \& Technical: Essex, U.K., 1989; p 399.
$\mathrm{NaHCO}_{3}(150 \mathrm{~mL})$ and stirred at reflux for $5 \mathrm{~h}$. The resulting solution was treated with $6 \mathrm{M} \mathrm{H}_{2} \mathrm{SO}_{4}$ until complete precipitation $(\mathrm{pH}=2)$. The product was filtered, washed with water to neutral $\mathrm{pH}$, and dried under vacuum for $6 \mathrm{~h}$ a $40{ }^{\circ} \mathrm{C}$. Elemental analysis: $\% \mathrm{~S}=8.5 \pm 0.1$ for three different samples.

Silylation of Sulfochlorinated PEEK: Synthesis of SOSiPEEK. Two different polymers were prepared by varying the amount of silicon: SOSiPEEK/25 and SOSiPEEK/50 containing $25 \%$ and $50 \%$ of silylated repeat units, respectively. The procedure for SOSiPEEK/25 is reported.

Sulfochlorinated PEEK (2.5 g, 6.5 mequiv) was dissolved, under nitrogen, in anhydrous THF $(300 \mathrm{~mL})$. After the mixture was cooled to $-60{ }^{\circ} \mathrm{C}, N, N, N^{\prime}, N^{\prime}$-tetramethylethylenediamine (TMEDA, 3.0 $\mathrm{mL}, 19.8 \mathrm{mmol})$ and an excess of BuLi $(2.5 \mathrm{M}$ in hexane, $7.9 \mathrm{~mL}$, $19.8 \mathrm{mmol}$ ) were added, and the orange solution was stirred for 6 $\mathrm{h}$ at $-60{ }^{\circ} \mathrm{C} . \mathrm{SiCl}_{4}(0.19 \mathrm{~mL}, 1.6 \mathrm{mmol})$ was then added dropwise and the solution was slowly warmed to room temperature and then kept at reflux for $12 \mathrm{~h}$. After the solution was cooled to RT, the precipitate formed was filtered and rapidly washed with anhydrous THF. The product was then hydrolyzed following the procedure previously reported for the synthesis of SOPEEK. The product obtained was dried under vacuum for $6 \mathrm{~h}$ at $40{ }^{\circ} \mathrm{C}$.

Structural and Thermal Characterization. ${ }^{1} \mathrm{H}$ and ${ }^{13} \mathrm{C}$ NMR spectra were recorded with a Bruker Avance 400 spectrometer operating at 400.13 and $100.56 \mathrm{MHz}$, respectively. DMSO- $d_{6}$ was used as solvent for ${ }^{1} \mathrm{H}$ spectra while ${ }^{13} \mathrm{C}$ NMR spectra were recorded in DMSO, using $\mathrm{D}_{2} \mathrm{O}$ as external lock. Chemical shifts (ppm) are referenced to tetramethylsilane (TMS).

$\Delta H_{\mathrm{f}}$ were calculated on the optimized geometries obtained by semiempirical methods (AM1) using the Hyperchem program. ${ }^{21}$ Geometric optimizations were terminated when the energy difference among successive iterations was lower than $4.18 \times 10^{-3} \mathrm{~kJ} /$ mol.

Attenuated total reflectance Fourier transform infrared (ATR/ FTIR) spectra were collected in the range $4000-550 \mathrm{~cm}^{-1}$, on a Nicolet 870 E.S.P. with a Golden Gate MK2 Diamond Specac cell. Spectra were recorded by positioning the samples on a cell platform operating at room temperature (32 scans, $2 \mathrm{~cm}^{-1}$ resolution).

FTIR spectra of samples heated to different temperatures were collected in the range $4000-400 \mathrm{~cm}^{-1}$ (32 scans, $2 \mathrm{~cm}^{-1}$ resolution) with a Bruker Equinox 55. The samples were in the form of films with a thickness of ca. $5 \mu \mathrm{m}$.

Thermogravimetric analysis (TGA Q500, TA Instruments) measurements were performed between 25 and $800{ }^{\circ} \mathrm{C}$ with a heating rate of $5 \mathrm{~K} / \mathrm{min}$ under air flux in platinum sample holders. The differential scanning calorimetric (DSC 92, SETARAM) measurements were performed between 25 and $580{ }^{\circ} \mathrm{C}$ in air, always with a heating rate of $5 \mathrm{~K} / \mathrm{min}$.

\section{Results and Discussion}

NMR Study of Polymeric Structures. Post-sulfonation of PEEK can be performed in several ways with different sulfonating agents, such as concentrated sulfuric acid, chlorosulfonic acid, sulfur trioxide, a sulfur trioxide - triethyl phosphate complex, or trimethylsilylchlorosulfonate..$^{22-25}$ Significant differences exist in the reports on the use of $\mathrm{HSO}_{3} \mathrm{Cl}$ as sulfonating agent: some authors report, in fact, that this reagent induced chain cleavages and polymer degradation during the reaction ${ }^{22}$ and, others, that no

(21) Hyperchem Release 5.11, Hypercube Inc. 1999.

(22) Bishop, M. T.; Karasz, F. E.; Russo, P. S.; Langley, K. H Macromolecules 1985, 18, 86. 
Scheme 1. Synthetic Route for the Synthesis of SOPEEK<smiles>COc1ccc(Oc2ccc(C(=O)c3ccc(C)cc3)cc2)cc1</smiles><smiles></smiles>

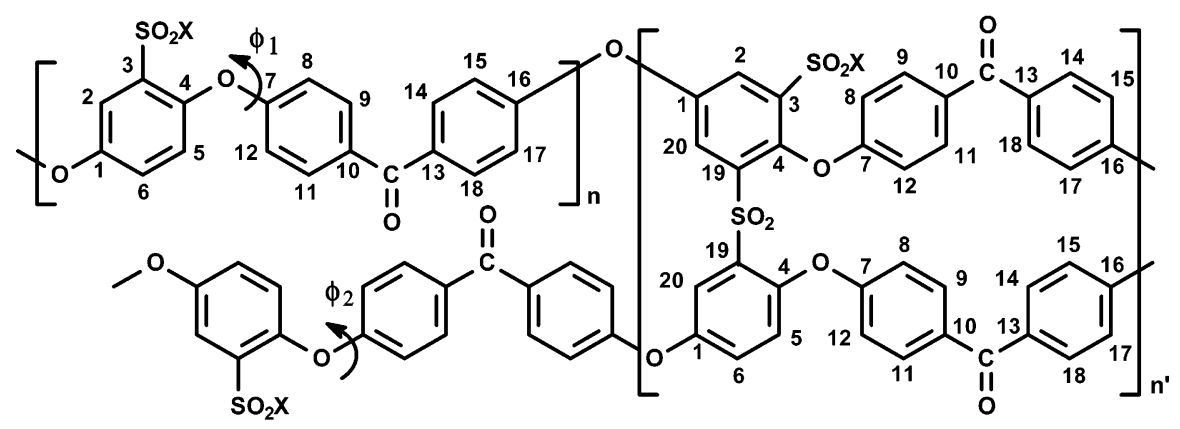

$\mathrm{X}=\mathrm{Cl}, \mathrm{OH}$

Table 1. ${ }^{1} \mathrm{H}$ NMR Data of SOPEEK ${ }^{a}$

\begin{tabular}{cccl}
\hline label & $\delta(\mathrm{ppm})$ & intensity $^{b}$ & \multicolumn{1}{c}{ assignment $^{b}$} \\
\hline A & 8.22 & 0.2 & 20 \\
B & $7.83-7.75$ & 4.0 & $9,11,14,18$ \\
C & $7.51-7.48$ & 0.8 & 2 \\
D & $7.22-6.95$ & 5.7 & $5,6,8,12,15,17$
\end{tabular}

${ }^{a}$ Assignments refer to the numbering shown in Scheme 1 and labels refer to Figure $1 .{ }^{b}$ As number of hydrogens.

degradation was observed. ${ }^{26}$ In our experimental conditions, no degradation was detected, but only sulfonation and crosslinking between sulfonic groups with the formation of $\mathrm{SO}_{2}$ bridging moieties was observed, as shown in Scheme 1 and demonstrated by analysis of the NMR and ATR/FTIR spectra of the products.

Figure 1a shows the ${ }^{1} \mathrm{H}$ NMR spectrum of the hydrolyzed product (SOPEEK) at $25{ }^{\circ} \mathrm{C}$. Four main groups of resonances, labeled $\mathrm{A}-\mathrm{D}$, are present. Assignments are based on literature data ${ }^{27,28}$ and reported in Table 1 . The main difference observed with respect to the spectrum reported for PEEK sulfonated in concentrated sulfuric acid (SPEEK) ${ }^{27}$ is the presence of a new resonance at $8.25 \mathrm{ppm}$ (A). Such chemical shift is characteristic of a hydrogen atom in the ortho position to a $\mathrm{SO}_{2}$ group, ${ }^{28}$ demonstrating the occurrence of cross-linking. The extent of cross-linking was evaluated by the relative intensities of resonances $\mathrm{A}$ and $\mathrm{B}$ : the environment of $\mathrm{H} 9, \mathrm{H} 11, \mathrm{H} 14$, and $\mathrm{H} 18$ is not modified by cross-linking so that if a value of $4 \mathrm{H}$ is attributed to

(23) Bauer, B.; Jones, D. J.; Roziere, J.; Tchicaya, L.; Alberti, G.; Massinelli, M.; Peraio, A.; Besse, S.; Ramunni, E. J. New. Mater. Electrochem. Syst. 2000, 3, 93.

(24) Okawa, T.; Marvel, C. S. J. Polym. Sci., Polym. Chem. Ed. 1985, 23, 1231.

(25) Genova-Dimitrova, P.; Baradie, B.; Foscallo, D.; Poinsignon, C.; Sanchez, J. Y. J. Membr. Sci. 2001, 185, 59.

(26) Trotta, F.; Drioli, E.; Moraglio, G.; Baima Poma, E. J. Appl. Polym. Sci. 1998, 70, 477.

(27) Xing, P.; Robertson, G. P.; Guiver, M. D.; Mikhailenko, S. D.; Wang, K.; Kaliaguine, S. J. Membr. Sci. 2004, 219, 95.

(28) Sumner, M. J.; Harrison, W. L.; Weyers, R. M.: Kim, Y. S.; McGrath, J. E.; Riffle, J. S.; Brink, A.; Brink, M. H. J. Membr. Sci. 2004, 239, 199.

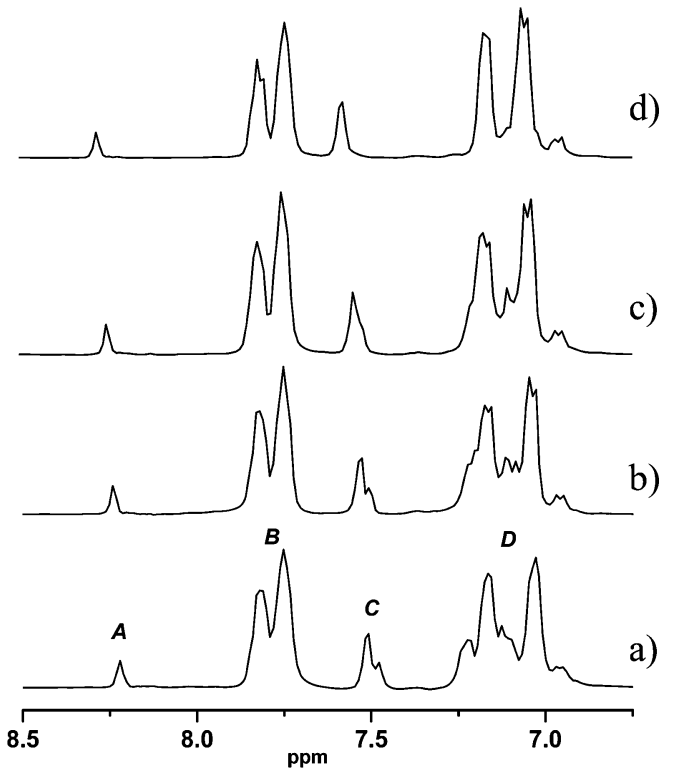

Figure 1. ${ }^{1} \mathrm{H}$ NMR spectra of SOPEEK at (a) $298 \mathrm{~K}$, (b) $310 \mathrm{~K}$, (c) 320 $\mathrm{K}$, and (d) $350 \mathrm{~K}$. Labels refer to the assignments reported in Table 1.

resonance $\mathrm{B}$, the intensity of resonance $\mathrm{A}(\mathrm{H} 20)$ corresponds directly to the degree of cross-linking ( $\mathrm{DCL}=0.2$ ), which involved $20 \%$ of the monomeric units.

Resonance $\mathrm{C}$ is due to hydrogens ortho to $-\mathrm{SO}_{3} \mathrm{H}(\mathrm{H} 2)$; its intensity was used to evaluate the degree of sulfonation (calculated as the number of $-\mathrm{SO}_{3} \mathrm{H}$ groups per monomeric unit that did not undergo condensation), which resulted in $\mathrm{DS}=0.8$.

At variance with that observed for SPEEK, in the spectrum of cross-linked SOPEEK (Figure 1a) resonance C is comprised of two nonequivalent peaks. Spectra were recorded at different temperatures (Figure $1 \mathrm{~b}-\mathrm{d}$ ) and the two peaks merged into a single one at $350 \mathrm{~K}$. The process is reversible and the original spectrum was restored upon cooling. Such behavior can be rationalized by taking into account the possible existence of different conformations. ${ }^{29}$ The crosslinking reaction produces, in fact, asymmetry in the unit next 


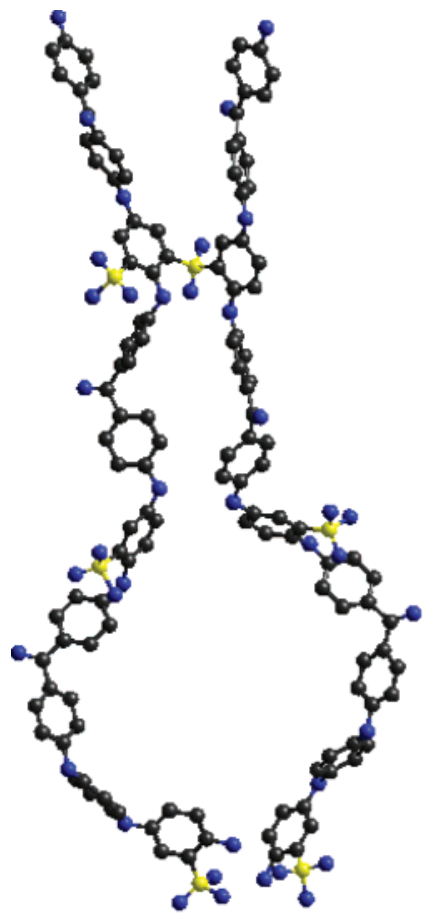

$\mathrm{A}\left(0^{\circ}, 0^{\circ}\right)$

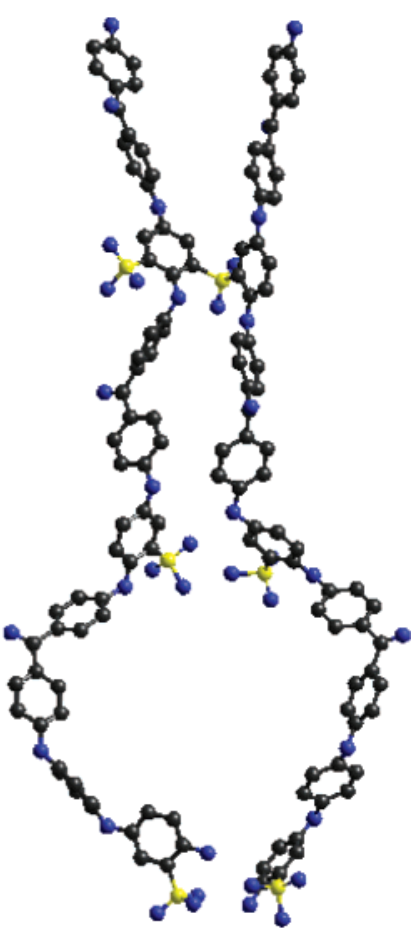

$\mathrm{B}\left(180^{\circ}, 180^{\circ}\right)$

Figure 2. Representation of the two extreme species derived from the restricted rotation of SOPEEK. Hydrogen atoms are omitted for the sake of clarity.

to the cross-linked one, so that rotation about the ethereal bonds, shown by the arrows in Scheme 1, generates different species.

To obtain more information about the energy barrier, we carried out semiempirical calculations on trimeric units (see Experimental Section). Given the high number of degrees of freedom in the aromatic structures under investigation, we did not carry out a systematic study of the potential energy surfaces, but only varied (in $90^{\circ}$ steps) the torsional angles $\phi_{1}$ and $\phi_{2}$ in the $n$ repeat unit (see Scheme 1). Figure 2 shows the two extreme conformations derived from rotation of the ether linkage. It is not the absolute values of $\Delta H_{\mathrm{f}}$ of the various species that should be considered, but only their variation. ${ }^{30}$ The most stable form resulted in the $\left(0^{\circ}, 0^{\circ}\right)$ species A. The difference between the $\Delta H_{\mathrm{f}}$ values relative to species $\mathrm{A}$ and $\mathrm{B}$ resulted in $60 \mathrm{~kJ} \mathrm{~mol}^{-1}$, in agreement with the existence of a restricted rotation at room temperature.

Figure 3 shows the ${ }^{13} \mathrm{C}$ NMR spectra of SOPEEK (Figure $3 \mathrm{a}$ ) and SPEEK with DS $=0.8$ (Figure $3 \mathrm{~b}$ ). Comparison of the two spectra allowed assigning all the resonances present in the spectrum of SOPEEK to the structure shown in Scheme 1, thus confirming that no degradation of the polymer occurred during the sulfonation reaction. The lack of resonances at 152.0 and $122.7 \mathrm{ppm}$, present in the spectrum of SPEEK and due to the non-sulfonated polymer, confirmed ${ }^{1} \mathrm{H}$ NMR data from which $(\mathrm{DS}+\mathrm{DCL})=1$. In Figure $3 \mathrm{a}$, the new peaks at 141.2 and $127.5 \mathrm{ppm}$ are due to

(29) Testa, B. Principles of Organic Stereochemistry; Marcel Dekker: New York, 1979.

(30) Licoccia, S.; Di Vona, M. L.; Paolesse, R. J. Org. Chem. 1998, 63, 3190 .

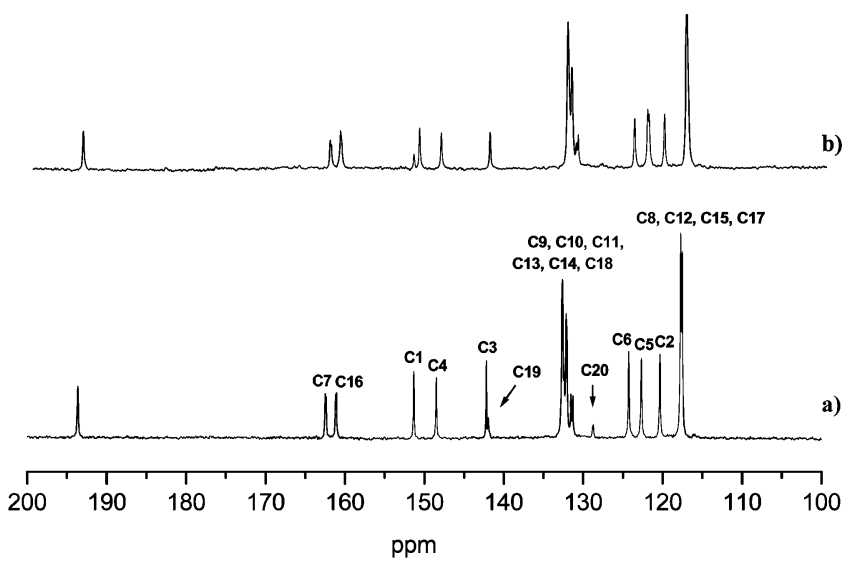

Figure 3. ${ }^{13} \mathrm{C}$ NMR spectra of (a) SOPEEK and (b) SPEEK.

the quaternary $\mathrm{C}$ atoms bound to the $\mathrm{SO}_{2}$ moiety $(\mathrm{C} 19)$ and to $\mathrm{C} 20$, respectively.

Because of its solubility in organic solvents, it was possible to use the $-\mathrm{SO}_{2} \mathrm{Cl}$ precursor of SOPEEK to carry out functionalization reactions in homogeneous conditions. This represents a great experimental advantage with respect to previously reported work. ${ }^{16}$ Preparing silylated SPEEK from its acidic form required critical steps involving several water treatments to eliminate excess sulfuric acid, which lead to partial loss of the product because of the solubility in water of SPEEK with high DS. Furthermore, to be used as a reactant in a lithiation reaction, the polymer needed to be very carefully dried. The introduction of $-\mathrm{Si}(\mathrm{OH})_{3}$ residues covalently bound to SOPEEK was now achieved by reacting its solution in anhydrous THF with buthyllithium at low temperature, and subsequent reaction with $\mathrm{SiCl}_{4}$ followed by hydrolysis. The position of silylation on the polymer 
Scheme 2. Synthetic Route for the Synthesis of SOSiPEEK
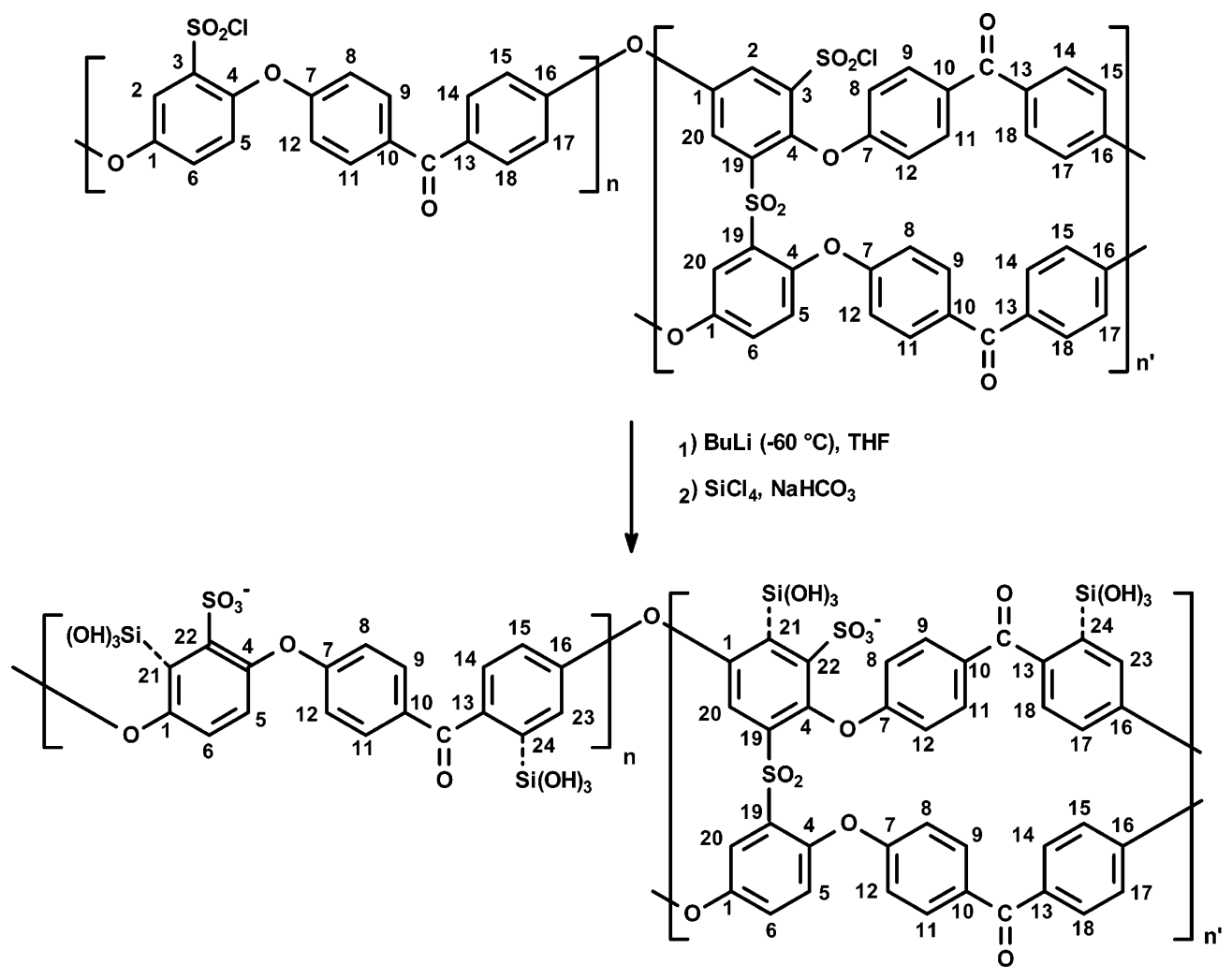

backbone is determined by the directing properties of the substituents. In the case of SPEEK the electronic effect of the carbonyl group and the coordinative ability of the sulfonic groups lead to the formation of two products. ${ }^{16}$ The same effect can be expected to occur in the present case and the possible products are shown in Scheme 2 where dotted lines were used to indicate $\mathrm{C}-\mathrm{Si}$ bonds. For the sake of clarity, only one structure is shown in Scheme 2, but it should be considered that different formulas could have been drawn given the equivalence, with respect to silylation, of positions 14, 18, and 24.

Two reactions were carried out with different monomeric unit/silicon ratios, namely, 1:0.25 (SOSiPEEK/25) and 1:0.5 (SOSiPEEK/50).

Figure 4 shows the ${ }^{1} \mathrm{H}$ NMR spectrum of SOSiPEEK/50. The only relevant difference that can be observed with respect to the spectrum of SOPEEK (Figure 1a) is the new peak at $7.6 \mathrm{ppm}$, which can be attributed to $\mathrm{H} 23$, ortho to a silicon atom. ${ }^{31}$

Figure 5 shows the ${ }^{13} \mathrm{C}$ NMR spectrum of SiSOPEEK/50 in DMSO. The large number of polar substituents introduced in the polymer lead to the formation of a gel, thus increasing the line width of the resonances. New peaks due to carbon atoms directly linked or ortho to silicon atoms can be clearly identified (C21, C22, C23, and C24). ${ }^{31}$

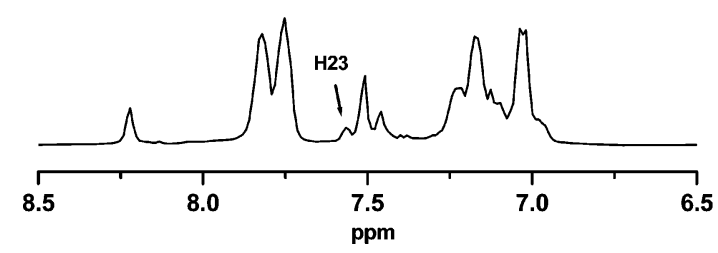

Figure 4. ${ }^{1} \mathrm{H}$ NMR spectrum of SOSiPEEK/50.
ATR/FTIR Study of Membranes. To verify the possibility of using these new hybrid polymers as electrolytes in PEMFCs, casting from DMSO solutions of SOPEEK, SOSiPEEK/25, and SOSiPEEK/50 was performed and transparent homogeneous membranes were obtained.

The membranes were characterized by ATR/FTIR spectroscopy. The spectra of the three samples are reported in Figure $6 \mathrm{~b}-d$ and compared with the spectrum of SPEEK with $\mathrm{DS}=0.9$ derived from sulfonation in concentrated $\mathrm{H}_{2}$ $\mathrm{SO}_{4}$ (Figure 6a). All spectra are dominated by PEEK absorptions. ${ }^{16,32,33}$ Subtraction of the spectrum of SPEEK from that of SOPEEK is shown in Figure 6e, to highlight the signals characteristic of this new sample. Absorptions due to aromatic sulfonic groups are clearly observed at 1185 $\mathrm{cm}^{-1}\left(\nu_{\mathrm{as}}-\mathrm{SO}_{3} \mathrm{H}\right), 1020 \mathrm{~cm}^{-1}\left(\nu_{\mathrm{sym}}-\mathrm{SO}_{3} \mathrm{H}\right)$, and $965 \mathrm{~cm}^{-1}(\delta$ $\left.\mathrm{SO}_{3} \mathrm{H}\right){ }^{34}$ The presence of 1:2:4-substituted phenyl rings is demonstrated by the occurrence of absorptions at 1225 and $1080 \mathrm{~cm}^{-1} .35$ This spectrum also displays bands characteristic of aromatic sulfone moieties: $1210 \mathrm{~cm}^{-1}$ (shoulder, $v_{\mathrm{as}} \mathrm{SO}_{2}$ ), $1065 \mathrm{~cm}^{-1}$ (tail, $v_{\mathrm{s}} \mathrm{SO}_{2}$ ), and $950 \mathrm{~cm}^{-1}\left(v_{\mathrm{s}} \mathrm{S}=\mathrm{O}\right)$, with the scissoring mode of the $\mathrm{SO}_{2}$ group at $610 \mathrm{~cm}^{-1}$. These signals are within the range expected for S-bonded sulfone. ${ }^{35-37}$ The $\mathrm{S}=\mathrm{O}$ stretching vibration of diphenyl sulfone, $\mathrm{Ph}-\mathrm{SO}_{2}-$

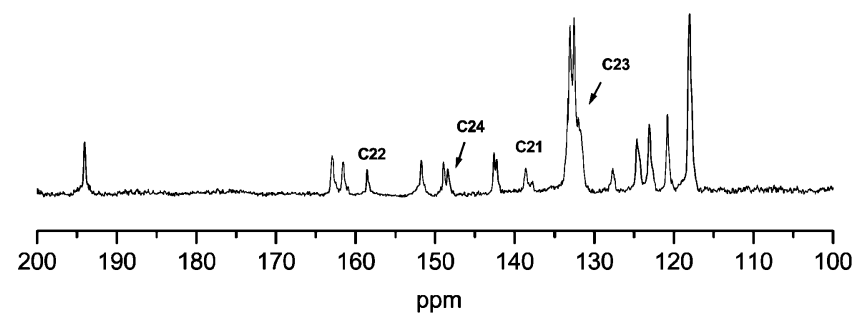

Figure 5. ${ }^{13} \mathrm{C}$ NMR spectrum of SOSiPEEK/50. 


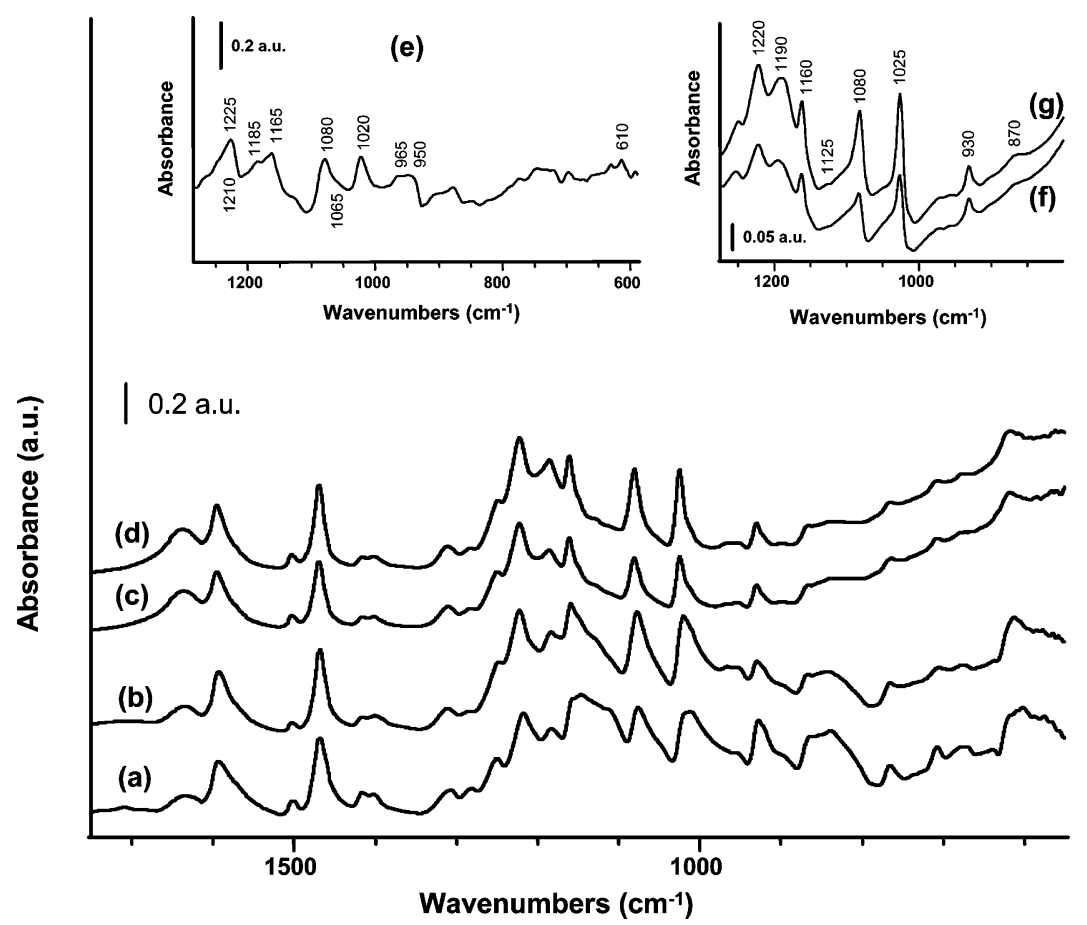

Figure 6. ATR/FTIR spectra of (a) SPEEK, (b) SOPEEK, (c) SOSiPEEK/25, (d) SOSiPEEK/50, and (e)/(g) subtraction spectra [(e) = (b) - 1(a), (f) = (c) $-1(\mathrm{~b}),(\mathrm{g})=(\mathrm{d})-1(\mathrm{~b})]$.

$\mathrm{Ph}$, is present at $1165 \mathrm{~cm}^{-1} .35$ These results confirm both the sulfonation of PEEK and the cross-linking.

The ATR-FTIR spectra of SOSiSPEEK/25 and SOSiSPEEK/50 membranes are shown in Figure $6 c$,d, respectively. Again, both spectra are dominated by PEEK absorptions. ${ }^{16,32}$ To confirm that silicon is linked to the polymer chains, a window devoted to subtraction spectra is shown (Figure 6f: SOSiPEEK/25 - SOPEEK; Figure 6g: SOSiPEEK/50 - SOPEEK). The two bands at 930 and $870 \mathrm{~cm}^{-1}$, observed in the subtraction spectra, are typical of aromatic silanols. ${ }^{33}$ A third weak band at $1125 \mathrm{~cm}^{-1}$ can be attributed to the in-plane deformation of the ring, with some contribution from the $\mathrm{Si}-\mathrm{C}$ stretch. ${ }^{33,35}$ Moreover, a new component of the $v \mathrm{C}-\mathrm{O}-\mathrm{C}$ band appears at $1025 \mathrm{~cm}^{-1}$, indicating a perturbation of the $\mathrm{C}-\mathrm{O}-\mathrm{C}$ bond stretching due to the presence of a new substitution, i.e., the introduction of silicon. No bands due to $\mathrm{Si}-\mathrm{O}-\mathrm{Si}$ bonds were observed. ${ }^{35}$ The presence of 1:2:3:4-substituted phenyl rings is also demonstrated by the occurrence of absorptions at 1220,1160, and $1080 \mathrm{~cm}^{-1} \cdot 35$ A new component at $1190 \mathrm{~cm}^{-1}$, characteristic of the asymmetrical stretching vibration of the sulfonic acid group $\left(v_{\text {as }}-\mathrm{SO}_{3} \mathrm{H}\right)$, further supports polymer silylation. It should also be noted that the intensity of all bands connected with silicon substitution almost doubles going from SOSiPEEK/25 to SOSIPEEK/50, in agreement with the synthetic

(31) Dai, Y.; Guiver, M. D.; Robertson, G. P.; Bilodeau, F.; Kang, Y. S.; Lee, K. J.; Jho, J. Y.; Won, J. Polymer 2002, 43, 5369.

(32) Nguyen, H. X.; Ishida, H. Polymer 1986, 27, 1400.

(33) Nguyen, H. X.; Ishida, H. J. Polym. Sci., Polym. Phys. Ed. 1986, 24, 1079

(34) Kim, C. ; Choi, J. G.; Tak, T. M. J. Appl. Polym. Sci. 1999, 74, 2046.

(35) Bellamy, L. J. The infrared spectra of complex molecules, Vol. 1; Chapman and Hall: London, U.K., 1980.

(36) Lindberg, B. J. Acta Chem. Scand. 1967, 21, 841.

(37) Adzamli, I. K.; Libson, K.; Lydon, J. D.; Elder, R. C.; Deutsch, E. Inorg. Chem. 1979, 18, 303

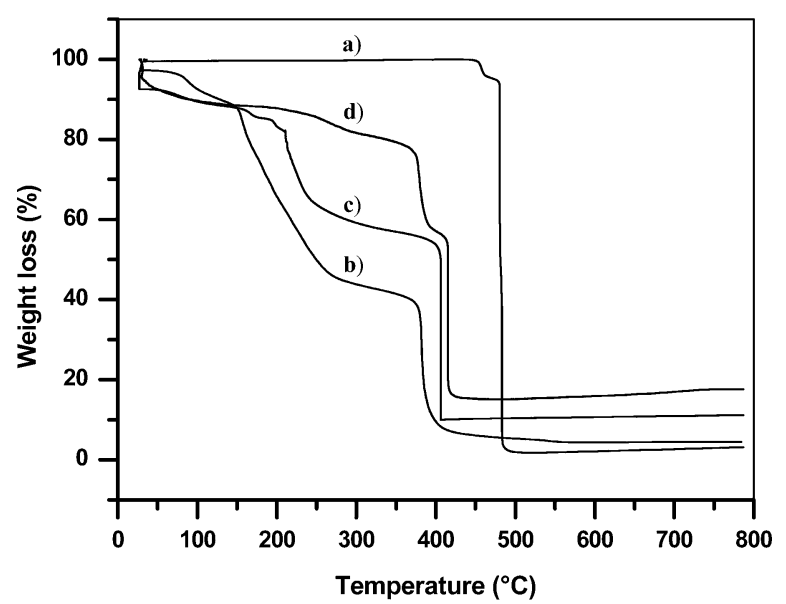

Figure 7. Thermogravimetric curves for (a) PEEK, (b) SOPEEK, (c) SOSiPEEK/25, and (d) SOSiPEEK/50.

stoichiometry and confirming the efficiency of the preparative procedure.

Thermal Analysis of Membranes. Figure 7 shows the TG curves relative to the newly synthesized samples, compared with the one relative to PEEK. Unsubstituted PEEK showed the highest thermal stability, and total decomposition occurred at about $480^{\circ} \mathrm{C}$. SOPEEK was clearly less stable and showed a $10 \%$ mass loss above $150^{\circ} \mathrm{C}$, which can be attributed to residual solvent removal. The second weight loss, between 250 and $300{ }^{\circ} \mathrm{C}$, corresponds to the decomposition of sulfonic groups. Complete pyrolysis occurred at about $400{ }^{\circ} \mathrm{C}$. Introduction of silicon increases the thermal stability, especially for SOSIPEEK/50.

DSC curves give complementary information about the thermal behavior. Figure 8 shows the curves for SOSIPEEK/ 25 (Figure 8a) and SOSIPEEK/50 (Figure 8b). After a small endothermic signal around $120^{\circ} \mathrm{C}$, corresponding to the loss 

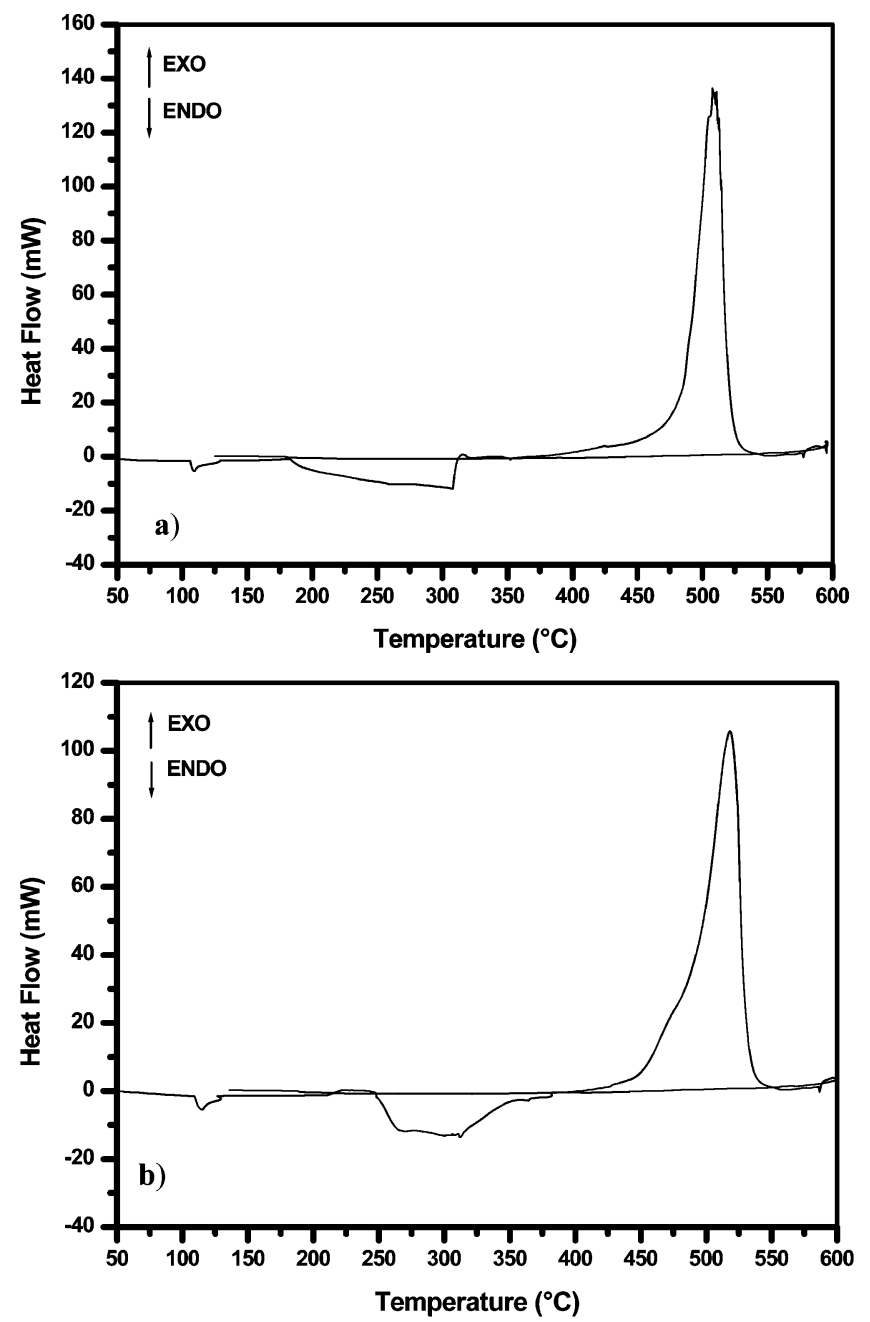

Figure 8. DSC curves for (a) SOSIPEEK/25and (b) SOSIPEEK/50.

of water, a broad endothermic effect was observed above $180{ }^{\circ} \mathrm{C}$ for SOSIPEEK $/ 25$ and above $250{ }^{\circ} \mathrm{C}$ for SOSIPEEK/ 50 , corresponding to the removal of sulfonate groups, in agreement with TG analysis. Large exothermic peaks due to the oxidative decomposition of the polymer were observed above 350 or $400{ }^{\circ} \mathrm{C}$, respectively.

Figure 9 shows the FTIR spectra of SOSIPEEK/25 measured on samples heated to selected temperatures. The spectra confirmed the above-discussed interpretation. The endothermic process is indeed the removal of sulfonate groups, the bands of which disappeared at $300{ }^{\circ} \mathrm{C}$ in the FTIR spectrum, whereas the aromatic bands were still present at such temperature, but nearly disappeared at $385{ }^{\circ} \mathrm{C}$. Finally, only a diffuse $\mathrm{Si}-\mathrm{O}$ band was observed at $800^{\circ} \mathrm{C}$, corresponding to total oxidation of the polymer.

The SOPEEK and SOSiPEEK membranes were insoluble in water, thus making feasible their electrochemical characterization in wet conditions. Preliminary data, obtained by electrochemical impedance spectroscopy, showed that the membranes exhibited high room-temperature conductivity

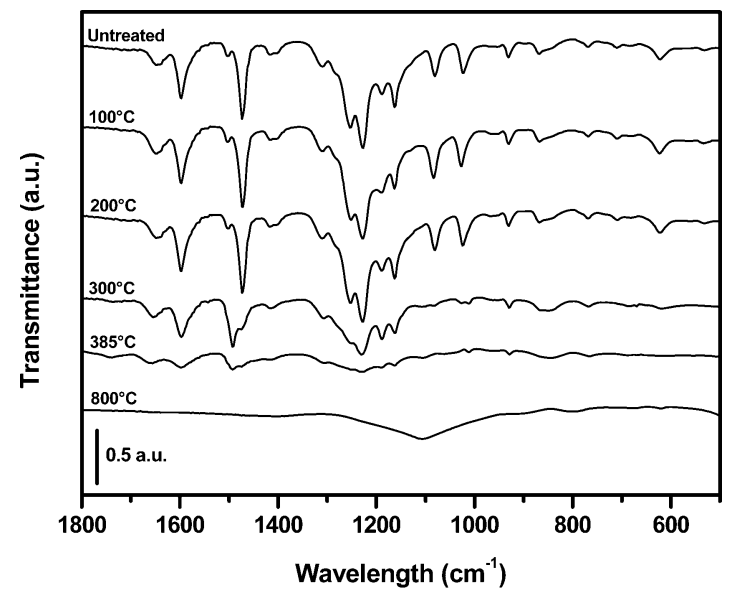

Figure 9. FTIR spectra of SOSIPEEK/25 heated to different temperatures.

values, in the range $10^{-3}-10^{-2} \mathrm{~S} \mathrm{~cm}^{-1}$. Further investigations on the electrochemical characterization of the hybrid crosslinked polymers and their application as electrolytes in PEMFCs are in progress.

\section{Conclusions}

Organic/inorganic hybrid proton exchange polymeric membranes based on cross-linked sulfonated polyetheretherketone have been synthesized and characterized. The crosslinking through $\mathrm{SO}_{2}$ moieties introduced via the sulfonation procedure lead to a precursor whose solubility in organic solvents allowed the carrying out of efficient and highly reproducible preparation of hybrid species where $-\mathrm{Si}(\mathrm{OH})_{3}$ groups were covalently bound to the polymeric backbone.

Thermal characterization showed that introduction of silicon increases the thermal stability of the membranes. The thermal stability increased with silicon content, but even at the composition 1:05 silicon units per monomeric unit (SOSiPEEK/50) the mechanical properties of the polymer were still suitable for the preparation of homogeneous, flexible membranes.

Formation of water insoluble hybrid materials made possible the preparation of membranes with good thermal stability and reduced swelling, whose conductivity seems to be promising for fuel cell applications. The introduction of $\mathrm{Si}(\mathrm{OH})_{3}$ units gives the possibility of further improving the hybrid characteristics by soft chemical methods such as sol/ gel processes.

Acknowledgment. This work has been financed by MIUR (FISR 2001 NUME Project Development of composite protonic membranes and innovative electrode configurations for Polymer Electrolyte Fuel Cells). Furthermore, the support by the FrancoItalian University in the framework of the Vinci program is gratefully acknowledged.

CM051546T 